\title{
KONTEKSTUALISASI MAKNA HADITS \\ TENTANG LARANGAN ISBAL
}

Jaya Sukmana ${ }^{1}$

assyuga_ast@yahoo.com

\begin{abstract}
ملخص
الحديث الذي هو المصدر الثاني في الإسلام بعد القرآن نحتاج إلى دراسته سواء من حيث سند أو الحديث المتن. ستتمكن

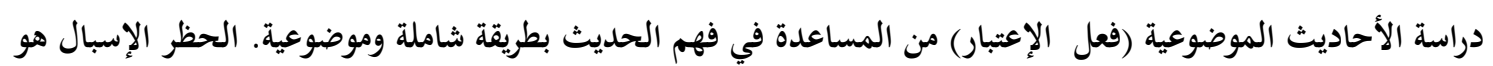

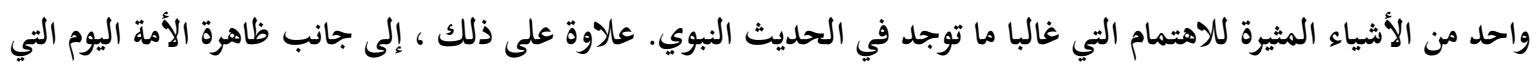

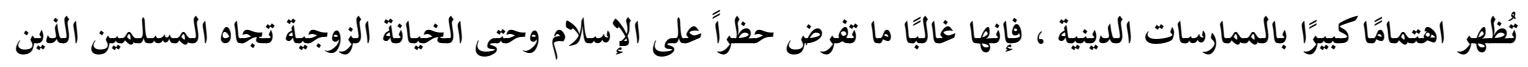

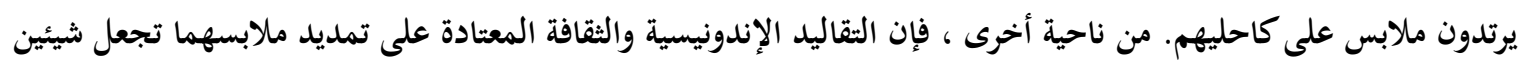

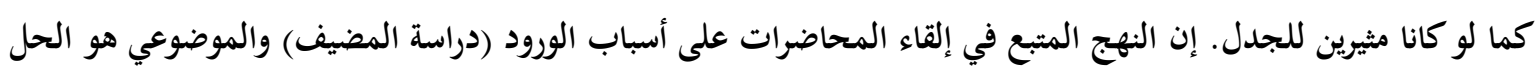

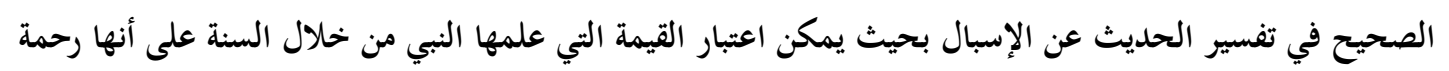
للعالمين.
\end{abstract}

كلمات البحث: الحديث ،الإسبال و المتكبّر

\section{A. Pendahuluan}

Hadits merupakan sumber hukum kedua setelah al-Qur'an yang sangat besar pengaruhnya dalam membentuk pemahaman dan pengamalan ajaran agama seorang muslim. Sumber Hadits, yakni Nabi saw, adalah wujud nyata dari ajaran wahyu. Adapun ulama ushul memandang tidak semua yang datang dari Nabi saw digolongkan sebagai Hadits yang harus diikuti, karena Nabi saw juga manusia yang berinteraksi dengan lingkungan dan waktu sehingga ada hal yang berasal rasullah saw, baik itu perkataan, perbuatan dan termasuk hadits yang harus diikuti. Problematika umat terhadap hukum Islam pada akhir ini memunculkan, terlihat diberbagai bentuk dan cara berpakaian dalam shalat. Mode yang selama ini dikuasai budaya Barat, telah merusak tatanan akhlaq kaum muda muslim di seluruh dunia. Akan tetapi, Islam menyodorkan busana yang sengaja dihadirkan sebagai

\footnotetext{
${ }^{1}$ Dosen tetap Prodi Ilmu Al-Qur'an \& Tafsir STAI Asy-Syukriyyah Tangerang
} 


\section{Jurnal Asy-Syukriyyah}

bukti kepedulian akan perbaikan akhlaq manusia. Taqshir (memendekkan)-bagi laki-laki celana yang terlihat sekarang ini sebagai salah satu bukti kepedulian kaum muslimin untuk membangkitkan kembali peradaban Islam yang telah lama tertutup kabut hawa nafsu manusia. Walaupun muslimin pada hal ini berbeda. Redaksi haditsnya adalah sebagai berikut :

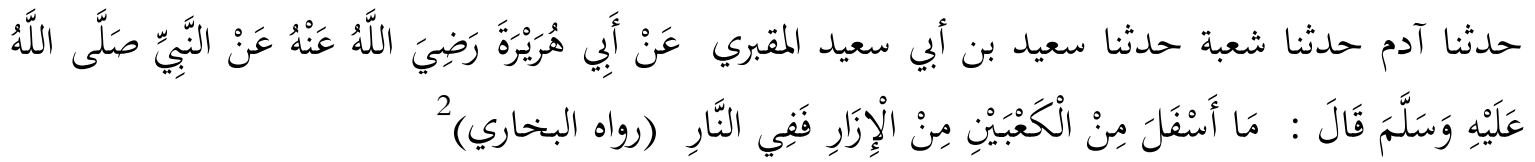

Dari Abu Hurairah ra., dari Nabi SAW beliau bersabda: "(Kain) yang panjangnya di bawah mata kaki tempatnya adalah neraka.'

حدثنا أحمد بن يونس حدثنا زهير حدثنا موسى بن عقبة عن سالم بن عبد الله عن أبيه رضي الله عنه عن

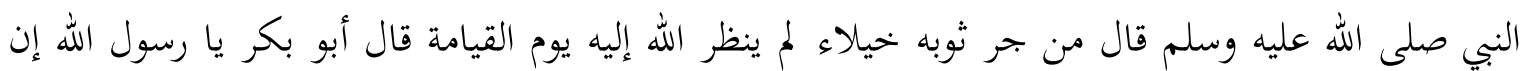
أحد شقي إزاري يسترخي إلا أن أتعاهد ذلك منه فقال النبي صلى الله عليه وسلم لست من يصن يصنعه خيلاء 3 (رواه البخاري)

Dari Abdullah bin Umar ra., dari Nabi SAW beliau bersabda: "Barangsiapa menjulurkan pakaiannya karena sombong, tidak akan dilihat oleh Allah pada hari kiamat. Abu Bakar lalu berkata, sesungguhnya salah satu sisi pakaianku akan melorot kecuali aku ikat dengan benar. Rasulullah SAW menjawab, engkau tidak melakukan itu karena sombong."

\section{B. Kritik Sanad}

1. Adam bin Abi Iyas

Dia adalah Abu al-Hasan al-Khurasani al-Baghdadi, seorang imam hadis yang telah berkelana ke berbagai negeri termasuk Iraq, Syam, Mesir dan Haramain. Ia dilahirkan

${ }^{2}$ Muhammad bin Isma'il al-Bukhari, Shahih Bukhari, (Kairo: Dar ar-Rayyan li at-Turats), Kitab alLibas, No. Hadis: 3665

${ }^{3}$ Muhammad bin Isma'il al-Bukhari, Shahih Bukhari, (Kairo: Dar ar-Rayyan li at-Turats), Kitab alLibas, No. Hadis: 5787 


\section{Jurnal Asy-Syukriyyah}

tahun $132 \mathrm{H}$ dan wafat tahun $220 \mathrm{H}$. Abu Hatim ar-Razi berkata tentangnya, "Dia adalah seorang tsiqah dan termasuk hamba Allah yang paling utama."

2. Syu'bah

Dia adalah Abu Bustham Ibnu al-Hajjaj bin al-Warad al-Azady, seorang imam, bergelar al-Hafizh dan Amir al-Mu'minin fil Hadits. Ulama penduduk Bashrah yang dirujuk kepadanya banyak persoalan. Beliau lahir tahun $80 \mathrm{H}$, di masa pemerintahan Abdul Malik bin Marwan.

Ia telah mengambil banyak periwayatan dari muhaddits lain, di antaranya: Anas bin Sirin, 'Amru bin Dinar, Manshur bin al-Mu'tamir, Zubaid bin al-Harits al-Yami dan lainlain. Yang mengambil hadis darinya: Abdullah bin Mubarak, Sufyan ats-Tsauri, Ibnu Ishaq dan lain-lain. Imam Syafi'i berkata tentang Syu'bah: “Andai bukan karena Syu'bah, barangkali hadits tidak akan dikenal di Irak." Hamad bin Zaid: "Jika aku menyelisihi Syu'bah dalam suatu hadis, maku aku akan condong kepadanya." Abu Daud athThayalusi: "Aku telah mendengar dari Syu'bah sejumlah 7000 hadits."

\section{Sa'id bin Abi Sai'd al-Maqbari}

Abu Sa'ad al-Laitsi adalah seorang muhaddits Hijaz yang tsiqoh. Gelar al-Maqbari disematkan karena ia tinggal di pemakaman Baqi’ di Madinah. Ia telah mengambil hadis dari banyak sahabat seperti Aisyah, Abu Hurairah, Sa'ad bin Abi Waqash, Ummu Salamah dan lain-lain. Perawi yang menyandarkan riwayat kepadanya, al-Laits bin Sa'ad, Ibnu Abi Dzi’b, Ibrahim bin Tahman, Malik bin Anas dan lain-lain.

“Tsiqotun Jalilun” adalah komentar yang diberikan Abdurrahman bin Harasy kepada Abu Sa'ad. Begitu juga al-Laits menilai beliau tsiqoh. Namun Abu Hatim hanya

\footnotetext{
${ }^{4}$ Muhammad bin Ahmad bin Utsman adz-Dzahabi, Siyar A'lam an-Nubala', (Kairo: Mu'assasah arRisalah, 1422 H), Juz-10, hal. 335

${ }^{5}$ Muhammad bin Ahmad bin Utsman adz-Dzahabi, Siyar A'lam an-Nubala', (Kairo: Mu'assasah arRisalah, 1422 H), Juz-7, hal. 203
} 


\section{Jurnal Asy-Syukriyyah}

menilainya shaduq karena telah terjadi kesilapan dalam periwayatan di 4 tahun masa tuanya. Ia wafat tahun $125 \mathrm{H}^{6}$

\section{Ahmad bin Yunus}

Ahmad bin Abdillah bin Yunus at-Tamimi al-Yarbu'i al-Kufi lahir pada tahun $132 \mathrm{H}$ dan wafat tahun $227 \mathrm{H}$. Ia mengambil hadis dari kakenya Yunus bin Abdillah bin Qais, dari Zaidah bin Qudamah, Abu Bakar bin 'Iyasy, Sufyan ats-Tsauri dan lain-lain. Telah mengambil darinya muhaddist kenamaan seperti Bukhari, Muslim, Abu Hatim, Abu Zar'ah ar-Razi dan lain-lain.

Beliau adalah seorang hafizh, al-imam dan al-hujjah dalam ilmu hadits. Ahmad bin Hanbal ketika ditanya oleh seseorang, "dari siapa saya menulis hadits?", maka ia menjawab, "pergilah kepada Ahmad bin Yunus, karena sesungguhnya ia Syaikhul Islam."7

\section{Zuhair}

Abu Khaitsamah Zuhair ibnu Hadij bin ar-Rahil al-Ju'fi al-Kufi adalah seorang alhafizh, al-mutqin, muhaddits yang mahsyur seantaro jazirah. Ia lahir pada tahun $95 \mathrm{H}$., dan telah banyak meriwayatkan hadis - di antaranya dari Sulaiman al-A'masy, Abu az-Zubair al-Makky, al-Aswad bin Qais dan lain-lain. Yahya bin Ma'in berkomentar tentangnya, "Zuhair adalah orang yang tsiqoh." Mu'adz bin Mu'adz berkata, "Apabila aku telah mendengar hadis dari Zuhair, maka aku tak keberatan untuk tidak mendengarnya lagi dari Sufyan ats-Tsauri." Ahmad bin Hanbal juga memberikan statement positif tentang Zuhair, "Dia salah satu 'alim terbaik.",

\section{Musa bin 'Uqbah}

${ }^{6}$ Muhammad bin Ahmad bin Utsman adz-Dzahabi, Siyar A 'lam an-Nubala', (Kairo: Mu'assasah arRisalah, 1422 H), Juz-5, hal. 216

${ }^{7}$ Muhammad bin Ahmad bin Utsman adz-Dzahabi, Siyar A'lam an-Nubala', (Kairo: Mu'assasah arRisalah, 1422 H), Juz-10, hal. 457

${ }^{8}$ Muhammad bin Ahmad bin Utsman adz-Dzahabi, Siyar A'lam an-Nubala', (Kairo: Mu'assasah arRisalah, 1422 H), Juz-8, hal. 183 


\section{Jurnal Asy-Syukriyyah}

Abu Muhammad al-Asadi adalah seorang maula sahabat, yaitu Ummu Khalid binti Khalid -istri az-Zubair bin al-'Awwam. Dia sempat menyaksikan banyak peperangan, dan termasuk yang paling pertama dalam menyusun esai sejarah itu. Telah meriwayatkan hadis dari banyak sahabat juga tabi'in, seperti Jabir, Alqamah bin Waqash, Abu Salamah, Kuraib dan lain-lain. Di antara yang mengambil riwayat darinya yaitu, Ibnu Juraij, Hafsh bin Maisarah, Yahya bin Sa'id al-Anshari dan lain-lain.

Ibrahim bin al-Mundzir bercerita, bahwa Malik bin Anas ketika ditanya, "Kisah peperangan siapa yang layak kami tulis?”, ia menjawab, “Tulislah kisah peperangannya Musa bin 'Uqbah, karena dia orang yang tsiqoh dan riwayatnya ashahhu al-maghazi." Ibnu Sa'ad berkomentar tentang Musa, "Dia adalah orang tsiqoh yang tsabt, namun hadisnya sedikit."

\section{Salim bin Abdullah}

Dia adalah cucu Amirul Mukminin Umar bin Khattab, seorang imam yang zuhud sekaligus mufti Madinah. Ia meriwayatkan beberapa hadis dari Aisyah, Abu Hurairah, Sa'id bin al-Musayyab, Abu Rafi' -maula Nabi SAW dan lain-lain. Di antara yang mengambil hadis darinya, Muhammad bin Wasi', az-Zuhry, Abu Bakar bin Hazm, 'Ashim bin Abdillah, Hanzhalah bin Abi Sufyan dan lain-lain.

Ibnu al-Mubarak berkata: “Fuqaha' Madinah yang dirujuk pendapatnya ada tujuh, Ibnu al-Musayyab, Sulaiman bin Yasar, Salim, al-Qasim, 'Urwah, Ubadillah bin Abdullah dan Kharijah bin Zaid. Tidak ada satupun hakim yang berani mengambil keputusan sebelum merujuk kepada mereka." 10

${ }^{9}$ Muhammad bin Ahmad bin Utsman adz-Dzahabi, Siyar A 'lam an-Nubala', (Kairo: Mu'assasah arRisalah, 1422 H), Juz-6, hal. 117

${ }^{10}$ Muhammad bin Ahmad bin Utsman adz-Dzahabi, Siyar A'lam an-Nubala', (Kairo: Mu'assasah ar-Risalah, 1422 H), Juz-4, hal. 458 


\section{Jurnal Asy-Syukriyyah}

\section{Takhrij Hadis}

Redaksi hadis pertama -selain datang dari Bukhari dalam Shahih-nya, juga dikeluarkan oleh muhaddits lain dengan sedikit perbedaan lafazh, namun maknanya secara garis besar sama. Ibnu Majah di dalam Sunan nomor hadis 3571:

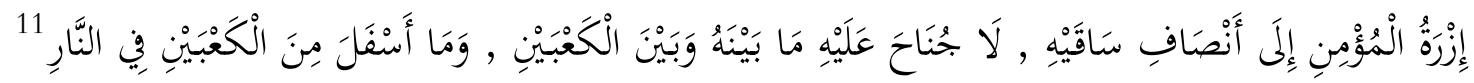

Ahmad bin Hanbal di dalam musnad nomor hadis 5561 dan an-Nasa'i nomor hadis $9328^{12}$ :

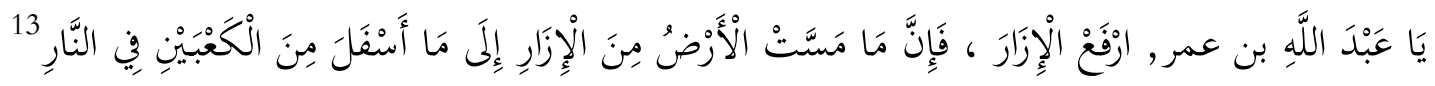

Adapun redaksi kedua, tidak ditemukan perbedaan lafazh yang signifikan dari riwayat perawi lain. Hadis dari Bukhari berbunyi من جر ثوبه خيلاء لم ينظر الله إليه يوم القيامة , sebagian

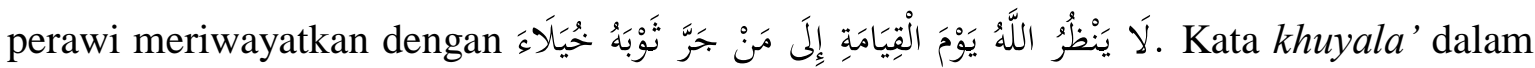
suatu riwayat lain diganti dengan bathra' -yang artinya sama-sama 'sombong'.

Dikeluarkan juga oleh Muslim nomor hadis $3894^{14}$, at-Tirmidzi nomor hadis $1650^{15}$, Abu Daud nomor hadis $3566^{16}$ dan Ahmad bin Hanbal nomor hadis 5956, 5982 dan $6035^{17}$.

${ }^{11}$ Muhammad bin Yazid bin Majah, Sunan Ibnu Majah, (Kairo: Dar Ihya al-Kutub al-Arabiyyah), Juz-2, No. Hadis: 3571 -dari jalur sahabat Sa'ad bin Malik

${ }^{12}$ Ahmad bin Syu'aib an-Nasa'i, as-Sunan al-Kubra, (Kairo: Mu'assasah ar-Risalah, $1421 \mathrm{H}$ ), No. Hadis 9328 dari jalurAbu Hurairah, no. Hadis 9349 dari jalur Abdullah bin Umar dan no. Hadis 9336 dari jalur Sa'ad bin Malik.

${ }^{13}$ Ahmad bin Hanbal, Musnad Ahmad bin Hanbal, (Kairo: Mu'assasah ar-Risalah), No. Hadis: 5561 -dari jalur sahabat Abdullah bin Umar. Terdapat beberapa hadis serupa di dalam kitabnya dari jalur Samrah bin Jundub no. Hadis 19647, Sa'ad bin Malik no. Hadis 10815 dan Abdurrahman bin Sakhr no. Hadis 9114.

${ }^{14}$ Muslim bin al-Hajjaj, Shahih Muslim, (Kairo: Dar Thayyibah, 1427 H), Kitab al-Libas wa azZinah, No. Hadis: 3894

${ }^{15}$ Abu Isa at-Tirmidzi, al-Jami’ al-Kabir, (Beirut: Dar al-Gharab al-Islami, 1996 M), Kitab alLibas, No. Hadis: 1650

${ }^{16}$ Sulaiman bin al-Asy'ats, Sunan Abu Daud, (Kairo: Dar ar-Risalah al-'Alamiah, 1430 H), Kitab al-Libas, No. Hadis 3566

${ }^{17}$ Ahmad bin Hanbal, Musnad Ahmad bin Hanbal, (Kairo: Mu'assasah ar-Risalah), ketiga jalur tersebut datang dari Abdullah bin Umar 


\section{Jurnal Asy-Syukriyyah}

Kata isbal sendiri justru ada di redaksi hadis lain, yaitu Abu Daud nomor hadis 4084 dan Ibnu Majah nomor hadis 2892:

$$
\text { وإياك وإسبال الإزار ؛ فإنه من المخيلة ، وإن الله لا يحب المخيلة18 }
$$

رأيت رسول الله صلى الله عليه وسلم أخذ بحجزة سفيان بن أبي سهل فقال يا سفيان لا تسبل إزارك فإن الله لا

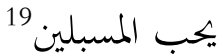

\section{Tafsir Kata}

1. Isbal (اسبال): adalah bentuk mashdar dari kata asbala, fi'il muta'addi yang membutuhkan objek (maf'ul bih). Artinya panjang, banyak, terjulur, terpancar. ${ }^{20}$

2. Izaar (ازار): Ibnu Manzhur berkata, كل من واراكَ وسَتَرَكَ. وتعني أيضا : الملحفة - Izar adalah apa saja yang menutupimu, termasuk selimut. ${ }^{21}$

3. Khuyala (خيلاء): dari kata khaala, artinya mengira. Karena kesombongan (al-kibr) dan rasa bangga (al-'ujub) akan membuat pelakunya mengira lebih tinggi dan orang lain lebih rendah. ${ }^{22}$

\section{E. Fiqh Hadis}

Kendatipun semua sanadnya berkualitas sahih dan bahkan mutawatir ${ }^{23}$-menurut sebagian ulama, karena di setiap thabaqah ada tiga orang perawi atau lebih, ternyata masih ditemukan silang pendapat dalam menghukumi musbil. Antara keharaman yang mutlak atau kebolehan dengan syarat.

Para ulama sepakat mengharamkan isbal jika karena sombong (khuyala'). Namun jika tidak dibarengi dengan kesombongan, ada tiga pendapat:

${ }^{18}$ Sulaiman bin al-Asy'ats, Sunan Abu Daud, (Kairo: Dar ar-Risalah al-'Alamiah, 1430 H), Kitab al-Libas, No. Hadis 34084

${ }^{19}$ Muhammad bin Yazid bin Majah, Sunan Ibnu Majah, (Kairo: Dar Ihya al-Kutub al-Arabiyyah), Juz-2, No. Hadis: 2892

${ }^{20}$ Diakses dari المعجم المعانى, pada tanggal 22 Oktober 2018

${ }^{21}$ Ibnu Manzhur, Lisan al- 'Arab, (Kairo: Dar Shadir, 2003 M), Juz-2, hal. 98

${ }^{22}$ Ibnu Manzhur, Lisan al- 'Arab, (Kairo: Dar Shadir, 2003 M), Juz-5, hal. 192

${ }^{23}$ Mahmud at-Thahhân, Taysîr Musthalah al-Hadis, (Beirut: Markaz al-Huda), hal. 78 


\section{Jurnal Asy-Syukriyyah}

Pertama, kebanyakan ulama pengikut madzhab yang empat me-makruh-kannya. Kedua, hukumnya tetap haram, karena zahir redaksinya adalah li at-tahrim dengan ancaman neraka. Wajib tepat/di atas mata kaki, sunnah di pertengahan betis, sebagaimana hadis Ibnu Majah dari Sa'ad bin Malik.

Inilah pendapat yang dipilih oleh Imam Ahmad bin Hanbal, al-Qadhi 'Iyadh, Ibnu Taimiyah dan madzhab Zahiriyah. ${ }^{24}$ Di antara dalil yang mereka ajukan adalah perkataan Ibnu Abdil Barr dalam at-Tamhid: “... adapun Abu Bakar tidak mengapa baginya (isbal), karena memang tidak ada kesengajaan dalam berbuat demikian (pakaian melorot bukan pilihan)." 25 Sulaiman al-Baaji dalam Syarh Muwattha' menyatakan: “...tidak mengapa isbal apabila memang itulah satu-satunya pakaian yang dimiliki. ${ }^{26}$ Mereka juga mengutip pernyataan Ibnu Hajar dalam Fath al-Bari:

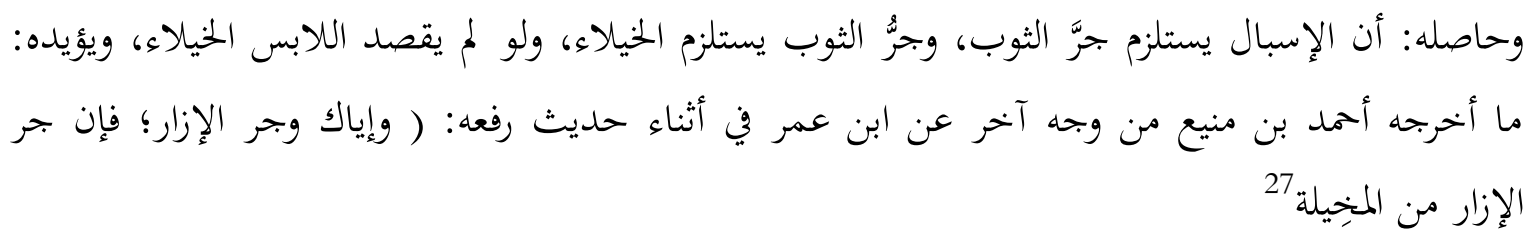

Bahwa Ibnu Umar diperintahkan untuk mengangkat sarungnya oleh Rasulullah walaupun beliau SAW tau kapasitas dia sebagai sahabat utama yang tidak mungkin sombong. Jadi bukan masalah 'memanjangkan sarung karena sombong', tapi 'memanjangkan sarung' itu sudah bentuk kesombongan. Bukan 'illat hukum kenapa perbuatan itu dilarang, tapi perbuatan itu berdiri sendiri pun sudah terlarang.

Selain itu, perilaku isbal juga lebih rentan terhadap kotoran dan najis yang mengancam kesempurnaan shalat seorang muslim. Dalilnya sebuah atsar dari Umar bin Khattab ra.:

${ }^{24}$ Muhammad bin Muflih al-Maqdisi, al-Adab asy-Syari'ah, (Beirut: Mu'assasah ar-Risalah, 1999 M), Juz-3, hal. 492

${ }^{25}$ Ibnu 'Abdil Barr al-Andalusi, at-Tamhid lima fi al-Muwaththa' min al-Ma'ani wa al-Asanid, 1412 H, Juz-3, hal. 249

${ }^{26}$ Sulaiman bin Khalaf al-Baaji, al-Muntaqa Syarh al-Muwathtah', (Kairo: Maktabah Sa'adah, 1332 H), Juz-9, hal. 315

${ }^{27}$ Ibnu Hajar al- 'Asqalani, Fath al-Bari, (Kairo: Dar ar-Risalah), Juz-10, hal. 264 


\section{Jurnal Asy-Syukriyyah}

لما رأى عمر شابَّا يمسّ ثوبُه الأرضَ -وعمر مشغولٌ بنفسه بعدما طُعن في آخر حياته دعاه وقال: "يا بني،

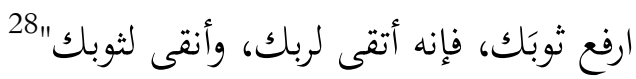

Kelompok ini juga membantah pendapat pertama dengan hadis syubhat, yakni perdebatan hukum yang ada di zona 'abu-abu' sebaiknya ditinggalkan. Redaksinya:

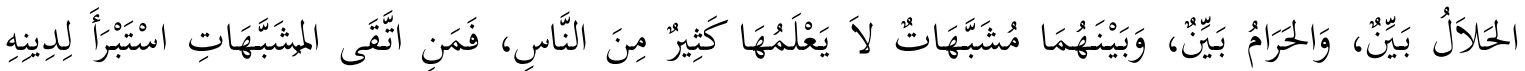

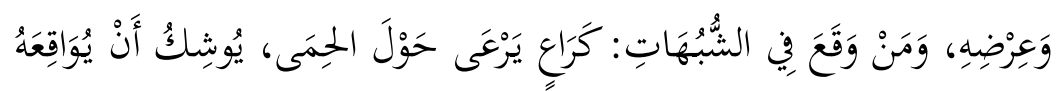

"Yang halal itu jelas, yang haram itu jelas. Diantaranya ada yang syubhat, yang tidak diketahui hukumnya oleh kebanyakan manusia. Barangsiapa menjauhi yang syubhat, ia telah menjaga kehormatan dan agamanya. Barangsiapa mendekati yang syubhat, sebagaimana pengembala di perbatasan. Hampir-hampir saja ia melewatinya" (HR. Muslim 1599)

Dan juga firman Allah SWT:

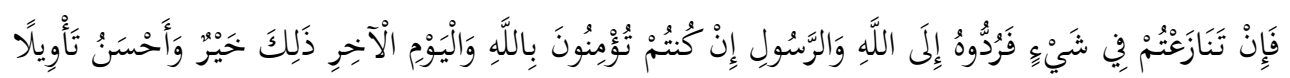

"Jika kamu berlainan pendapat tentang sesuatu, maka kembalikanlah ia kepada Allah (Al Qur'an) dan Rasul (sunnahnya), jika kamu benar-benar beriman kepada Allah dan hari kemudian. Yang demikian itu lebih utama (bagimu) dan lebih baik akibatnya" (QS. anNisa: 59)

Pendapat ketiga, membolehkan isbal yang tanpa disertai kesombongan. Di antara dalil yang mereka gunakan adalah kisah Imam Abu Hanifah:

أن أبا حنيفة ارتدي رداء ثمينا قيمته: 400 دينار وكان علي الأرض, فقيل له: أولسنا غينا عن ذلك؟ فقال إنا ذلك لذوي الخيلاء ولسنا منهم؟

Ia menyatakan bahwa ancaman musbil hanya berlaku bagi mereka yang melakukannya dengan motivasi berbangga diri. ${ }^{29}$ Fakta tersebut didukung oleh pernyataan adz-Dzahabi tentang Abu Hanifah:

${ }^{28}$ Umar bin Syabah, Tarikh Madinah, No. Hadis (mauquf): 1493

${ }^{29}$ Muhammad bin Muflih al-Maqdisi, al-Adab asy-Syari'ah, (Beirut: Mu'assasah ar-Risalah, 1999 M), Juz-3, hal. 492 


\section{Jurnal Asy-Syukriyyah}

$$
\text { كان أبو حنيفة جميل الوجه سري الثوب عطر الريح }
$$

Imam Nawawi menyatakan dalam syarh-nya:

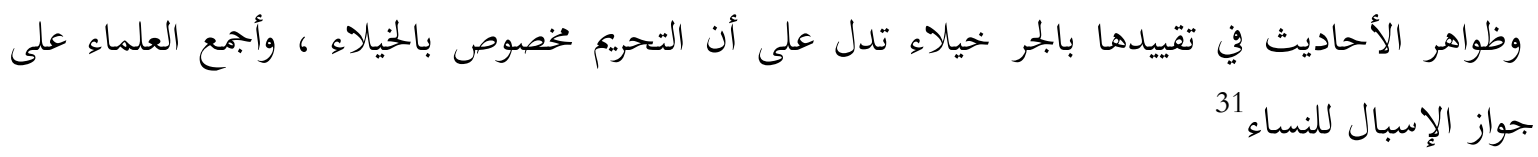

Rasulullah SAW juga bersabda:

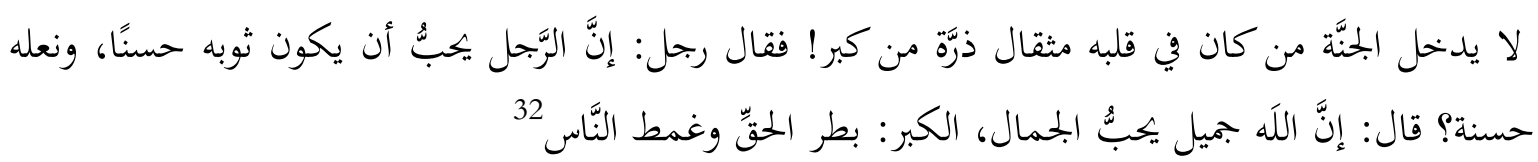

Bahwa kesombongan tidak melekat di dalam satu bentuk pakaian -sebagaimana dijelaskan Nabi SAW. Rasa sombong muncul ketika seseorang meremehkan manusia dan menolak kebenaran. Label 'haram' akan menempel pada setiap model baju/celana jika memang menjadikannya 'merasa lebih' dari yang lain.

Kain panjang yang berumbai sampai menyentuh tanah memang lambang budaya orang-orang kaya saat itu, maka hukum isbal harus dikontekstualisasikan penerapannya dalam kultur yang berlaku. Apabila dengan celana mengatung, gamis, kerudung besar justru membuat seseorang merasa lebih baik, tak ayal masuk juga ke dalam kategori khuyala'.

Hadis ini juga menjadi bukti bahwa Rasulullah mendambakan umatnya untuk tampil dan terlihat indah. Memperhatikan penampilan sehingga tidak ada halangan baginya untuk dapat bergaul dengan semua kalangan masyarakat -yang pada puncaknya lahirlah citra Islam sebagai agama bersih dan santun.

Adapun tentang kesucian dari najis, kelompok ketiga mengajukan sebuah hadis riwayat Ummu Salamah ra.:

${ }^{30}$ Muhammad bin Ahmad bin Utsman adz-Dzahabi, Siyar A 'lam an-Nubala', (Kairo: Mu'assasah ar-Risalah, 1422 H), Juz-6, hal. 391

${ }^{31}$ Abu Zakariya Yahya bin Syaraf, Syarh an-Nawawi 'ala Muslim, (Kairo: Dar al-Khair, 1416 H), Juz-2, hal. 251

${ }^{32}$ Muslim bin al-Hajjaj, Shahih Muslim, (Kairo: Dar Thayyibah, 1427 H), Kitab al-Iman, No. Hadis: 91 


\section{Jurnal Asy-Syukriyyah}

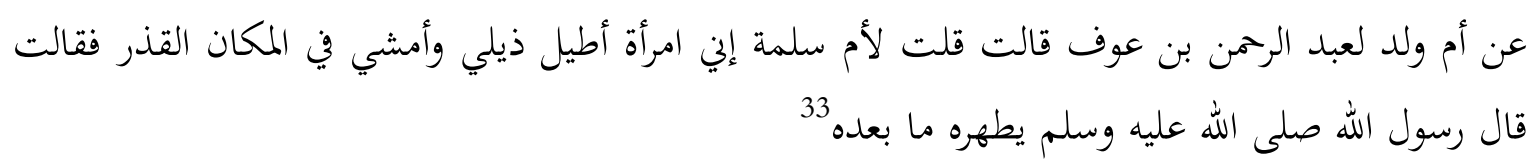

Ummu Salamah ra. pernah bertanya kepada Nabi SAW, "Ujung celana saya panjang (menjulur ke tanah) dan saya pernah melewati tempat yang kotor." Rasulullah menjawab, "Kotoran itu akan disucikan oleh tanah yang bersih setelahnya."

\section{F. Tarjih dan Kesimpulan}

Sebenarnya ketiga pendapat sama-sama memiliki dilalah yang mu'tabar dan didukung oleh kelompok ulama yang mu'tabar pula. Namun permasalahan terletak di redaksi hadis - dimana sebagian datang dengan larangan mutlak dan lainnya hanya ketika terikat dengan khuyala'. Apabila seseorang memahaminya dengan kaidah taqyid almuthlaq, maka tentulah syarat sombong merupakan suatu keniscayaan. Dan yang menganggap kasus isbal-nya Abu Bakar anomali, khusus diperuntukkan untuknya, 'minimal' hukum isbal itu makruh.

Jadi barangkali tidak bijak jika seorang muslim mencela satu sama lain dalam masalah furu' demikian - padahal telah diketahui runut ijtihad dan dasar argumen masing-masing kelompok.

Penulis sendiri lebih memilih pendapat yang membolehkan isbal jika tidak ada unsur kesombongan. Karena dalam bergaul, bermasyarakat, perlu diperhatikan juga 'urf dan kebiasaan yang berlaku. Jika seseorang hidup di tengah-tengah komunitas salafy --yang identik dengan celana cingkrang, silahkan blend in agar ia tidak merasa teralienasi. Namun jika ia berada di tengah-tengah warga yang belum terbiasa dengan itu, dikhawatirkan akan tumbuh rasa eksklusifitas, karena sebagaimana dijelaskan Ibnu al-Jauzi dalam Talbis Iblis, berbeda hasutan syetan untuk orang awam dan orang yang berilmu.

33 Abu Isa at-Tirmidzi, al-Jami’ al-Kabir, (Beirut: Dar al-Gharab al-Islami, 1996 M), Kitab athTharah 'an Rasulillah, No. Hadis: 143 


\section{Jurnal Asy-Syukriyyah}

\section{DAFTAR PUSTAKA}

Al-Mishrî, Jamal Ad-Dîn Ibn Mukrim Ibn Manzûr, Lisân Al-'Arab, Beirut : Dâr Shâdir, t.th

Al-Bukhari, Muhammad bin Isma'il, Shahih Bukhari, Kairo: Dar ar-Rayyan li at-Turats

Adz-Dzahabi, Muhammad bin Ahmad bin Utsman , Siyar A'lam an-Nubala', Kairo: Mu'assasah ar-Risalah, $1422 \mathrm{H}$

Ibnu Majah, Muhammad bin Yazid bin Majah, Sunan Ibnu Majah, Kairo: Dar Ihya alKutub al-Arabiyyah

Ahmad bin Hanbal, Musnad Ahmad bin Hanbal, Kairo: Mu'assasah ar-Risalah

An-Nasa'i, Ahmad bin Syu'aib, as-Sunan al-Kubra, Kairo: Mu'assasah ar-Risalah, $1421 \mathrm{H}$ An-Naisaburi, Muslim bin al-Hajjaj, Shahih Muslim, Kairo: Dar Thayyibah, 1427 H

At-Tirmidzi, Abu Isa, al-Jami' al-Kabir, Beirut: Dar al-Gharab al-Islami, 1996 M

Abu Daud, Sulaiman bin al-Asy'ats, Sunan Abu Daud, Kairo: Dar ar-Risalah al-'Alamiah, $1430 \mathrm{H}$

At-Thahhân, Mahmud, Taysîr Musthalah al-Hadis, Beirut: Markaz al-Huda

Al-Maqdisi, Muhammad bin Muflih, al-Adab asy-Syari'ah, Beirut: Mu'assasah ar-Risalah, $1999 \mathrm{M}$

Al-`Asqalani, Ibnu Hajar, Fath al-Bari, (Kairo: Dar ar-Risalah), 